\title{
O outdoor político: da mensagem visual ao eleitor
}

The political billboard: from visual message to the voter

\section{Fernanda Isabel Viana}

Doutora em Engenharia Têxtil pela Universidade do Minho - Portugal; mestre em Ciências da Comunicação pela Universidade Fernando Pessoa - Portugal; professora de Graduação e Mestrado em Ciências da Comunicação da Universidade Fernando

Pessoa - Portugal. E-mail: fviana@ufp.edu.pt

\section{Resumo}

A presente investigação incide sobre o outdoor político, procurando compreender o comportamento da mensagem estabelecida por ele, particularmente, nas suas vertentes plástica e textual. A necessidade premente de atingir o eleitorado levou ao recurso de instrumentos capazes de responder às expectativas e aos objetivos definidos. Deste modo, em relação à publicidade exterior, o outdoor surge como meio escolhido. A esfera pública vê-se, assim, invadida, em período eleitoral, por mensagens de caráter ideológico, ou não, que obedecem a determinados parâmetros, responsáveis por captar a atenção e mobilizar os eleitores.

Palavras-chave: outdoor; mensagem visual; publicidade.

\section{Abstract}

The political billboard is the focus of this research, with aims at understanding the behavior of its message, particularly concerning its plastic and textual aspects. Due to the urgent need to reach the electorate, tools are being used to reach better answers in relation to the expectations and goals. Therefore, the billboard is the medium of choice in terms of outdoor media. As a result, the public sphere is thereby invaded, at the period of election, by ideological messages, or not, obeying certain parameters in order to catch the attention and to mobilize voters.

Keywords: billboard; visual message; advertising. 


\section{O outdoor político: da mensagem visual ao eleitor}

\section{Introdução}

Em todo o mundo, desde sempre, as populações são fustigadas com estratégias sabiamente delineadas no sentido de alterar atitudes, comportamentos, crenças e convicções. A necessidade de despertar para uma mudança anunciada, quase sempre de caráter ideológico - mostrando a perspetiva de alteração política que levará, pressupostamente a uma melhor condição social e econômica - sempre surgiu como sustentação e razão de ser dos movimentos históricos, revolucionários ou não. Esta necessidade levou ao surgimento de novas formas de divulgação de ideias, de vontades e de quereres, tornando-se veículo efetivamente capaz de levar às populações a mensagem desejada, com efeitos sobre seu comportamento.

Sempre presente na esfera pública, localizado em espaços de grande movimentação viária, o outdoor tornou-se, ao longo do tempo, um instrumento de comunicação de massas potencializador da mensagem política. Levando em conta esta evidência, o principal enfoque deste trabalho teórico recai sobre a análise e o entendimento dos seus conteúdos visuais, de forma integrativa, considerando a linguagem plástica (contraste cromático, organização dos elementos ou sintaxe visual, textura e enquadramento visual) e a mensagem linguística.

Partindo de uma explanação teórica da palavra outdoor, com base no seu antecessor, o cartaz de rua, e dos seus conteúdos construtivos, particular destaque será dado à linguagem visual e verbal presente em outdoors políticos. Com base no estudo de vários autores, foi desenvolvida uma estrutura de análise aplicada ao estudo dos elementos que constituem diferentes outdoors utilizados em campanhas eleitorais em Portugal.

\section{Abordagem ao outdoor como instrumento político}

"Fora de porta" é, sem dúvida, a tradução portuguesa de outdoor. Face à amplitude contextual que lhe é inerente, sobretudo em relação à versatilidade da palavra, seu emprego pode suscitar alguma confusão. No entanto, para o estudo em questão, é interessante apenas abordar o outdoor aplicado no âmbito da publicidade e da propaganda política. Para alguns autores, o outdoor é o mesmo que publicidade exterior, ou seja, concretamente uma forma de comunicação visual que utiliza suportes que se encontram permanentemente na rua. Considerando esta constatação, o outdoor então engloba todo tipo de instrumento comunicacional, como: cartazes, propagandas (luminosas ou não) painéis eletrônicos, iluminados e luminosos, lonas, faixas, outdoor banner, mub, abrigo de ônibus, e até publicidade em veículos. Porém, outros autores defendem que o outdoor, geralmente no formato $8,0 \times 3,0 \mathrm{~m}$, é o produto tradicional da publicidade exterior, e também aquele que concentra a maioria do investimento publicitário nesta área. Tendo em vista o uso generalizado da palavra para um determinado tipo de meio publicitário, e ainda, o fato de existir um termo genérico e que identifique todos os suportes comunicacionais que se encontrem ao ar livre - publicidade exterior - , optou-se por enquadrar o outdoor como um meio de comunicação publicitária com estrutura de sustentação própria, de grande formato, com medidas entre 4,00 m e 8,00 m - resultado da soma de várias chapas com $0,80 \mathrm{~m}$ de comprimento por 3,00 $\mathrm{m}$ de altura - com o lado maior na base, localizado no exterior, em zonas de grande tráfego e locais de grande visibilidade.

Os primórdios do outdoor, tal como se entende, remontam ao final do século XIX, início do século XX - quando o cartaz se encontrava em toda a sua plenitude (é importante lembrar que este, enquanto suporte de mensagens de caráter publicitário, surgiu quase um século antes). Segundo a Outdoor Advertising Association of America (OAAA), o billboard ${ }^{1}$ surgiu em 1900, nos Estados Unidos, quando as grandes empresas começaram a revelar algum interesse na utilização deste meio:

In 1900, a standardized billboard structure was established in America, and ushered in a boom in national billboard campaigns. Confident that the same ad would fit billboards from coast to coast, big advertisers like Palmolive, Kellogg, and CocaCola began mass-producing billboards as part of a national marketing effort. ${ }^{2}$

A aceitação e o uso generalizado do outdoor, por parte do meio empresarial ou de potenciais anunciantes (como candidatos e partidos políticos) foram um processo gradativo, e sua maior evolução se deveu, em parte, à inadaptação física do cartaz, resultado das novas exigências da sociedade. Barnicoat (1997) estabelece o paralelismo entre o outdoor e o cartaz destacando dois fatores como sendo os principais responsáveis pela necessidade de aumentar as dimensões do cartaz: a importância de obter

1 Nos EUA, a palavra outdoor encontra-se associada ao que, em Portugal, convencionou-se chamar de publicidade exterior, enquanto billboard se refere ao outdoor.

2 [History of $\mathrm{OOH}$ ]. Disponível em <http://www.oaaa.org/ OutofHomeAdvertising/HistoryofOOH.aspx>. [Consultado em 24/10/2013]. 
maior impacto visual; e o aumento da velocidade dos meios de transportes. De fato, a busca intensa de um meio que melhor se adapte às exigências do mercado é uma realidade constante. Talvez por isso alguns especialistas cheguem até a afirmar que a criatividade dominou o setor da publicidade exterior, com a comercialização de espaços publicitários diferentes do que comummente se entende como suporte de publicidade exterior.

Vale a pena mencionar que tanto o cartaz como o outdoor, especialmente os que apresentam caráter comercial (sem considerar os de natureza política), têm o preceito de informar, seduzir, convencer, educar, levar à memorização, suscitar a necessidade, em suma, de fazer girar o mecanismo do consumo. A questão reside, essencialmente, na resposta inerente a cada um desses instrumentos, quando confrontados com as exigências da sociedade moderna. São inúmeros os exemplos que condicionam a eficácia dos meios de publicidade exterior: a expansão do tráfego de automóveis, a melhoria das estradas, que confere maior velocidade aos veículos, assim como o estresse diário, resultado da redução do tempo livre disponível. O desajuste do cartaz de rua em relação a esta nova sociedade pode ser a razão para a diminuição do seu emprego em campanhas publicitárias e de propaganda política. Por outro lado, a identidade ímpar do outdoor pode ser a base da sua ampla utilização. Assim, algumas variáveis que interferiram na vulgarização do outdoor destacam-se:

- A grande dimensão e a simplicidade das mensagens, responsáveis por proporcionar elevada legibilidade e, consequentemente, visualização por parte do público, sobretudo dos motoristas;

- O maior impacto visual, considerando o poder atrativo subjacente aos seus conteúdos visuais;

- A alta taxa de indivíduos atingidos pela mensagem: pedestres e motoristas;

- O baixo custo, tendo em conta o alto grau de exposições de um só suporte;

- A localização estratégica - seja de nível geográfico ou de postura elevada.

Percebe-se então que as fraquezas mais evidentes do cartaz de rua são, em contrapartida, pontos fortes do outdoor. Para além do apontado, a jornalista Graça Rosendo faz referência à legitimidade de sua utilização descontrolada em campanhas políticas. Ou seja, em Portugal, um preceito legal proíbe a colagem indiscriminada de cartazes pelas fachadas, paredes e muros de sustentação ou de vedação. Desse modo, a campanha no exterior passou a ser feita em estruturas próprias, montadas para isso, aproveitando os locais de boa visibilidade. Isso pode ser entendido como mais uma razão para a diminuição do uso do cartaz de rua em campanhas desta natureza.

Considerando a elevada procura por meios caracterizados por amplificar a mensagem a ser transmitida, particularmente em período eleitoral, o outdoor torna-se parte integrante da paisagem das cidades. Isto porque, de um lado, proporciona a legibilidade da mensagem e goza de elevado grau de notoriedade e visibilidade e, de outro, tem baixos custos de produção, instalação, manutenção e de aluguel do espaço. Camilo (2003) destaca o uso deste instrumento assegurando que "[...] aqueles que estão em melhor posição para desenvolver uma ação política utilizam sistematicamente o outdoor político nas suas campanhas eleitorais". É possível notar que, cada vez mais, este meio é visto como presença obrigatória entre os meios selecionados para a efetivação da comunicação política.

A preferência por meios de comunicação, vulgarmente do âmbito da publicidade, por parte dos candidatos e de partidos políticos, não é um fenômeno recente. Apenas para citar alguns exemplos, destacam-se: o artigo The BillposterDisplay Advertising, de março de 1903, no qual é referido o uso do outdoor numa campanha política daquele ano, em Chicago: "[...] was the most effective way of attracting the widest public attention", assim como, o exaustivo emprego deste instrumento na campanha que antecedeu a eleição de Margaret Thatcher como primeira ministra e, ainda, o outdoor utilizado na campanha presidencial de François Miterrand, caracterizado por uma mensagem simples e muito eficaz, cujo slogan ficou para sempre na memória dos franceses: "La force tranquille" (MAAREK, 1992).

\section{1 (Des)construindo o outdoor político}

Utilizando como referencial de análise a estrutura desenvolvida por Joly (1991) relativa à análise da mensagem visual, torna-se possível observar alguns dos pressupostos usados na construção dos conteúdos visuais do outdoor político. Para isso, serão considerados os elementos de mais importância na sua concepção, tendo como base os signos plásticos: cor, composição, textura, enquadramento, ângulo do ponto de vista objetivo e mensagem textual.

Caracterizada por estimular o observador e provocar nele sensações muito distintas, a cor é um dos elementos mais importantes na constituição das mensagens visuais. 


\section{O outdoor político: da mensagem visual ao eleitor}

De acordo com Dondis (2000, p.64):

[...] el color está cargado de información y es una de las experiencias visuales más penetrantes que todos tenemos en común [...] constituye una valiosísima fuente de comunicadores visuales [como também] tiene una gran fuerza y puede emplearse para expresar y reforzar la información visual.

Consequentemente, a cor revela-se eficaz na captação da atenção do público. Sobre este ponto de vista, Farina (1975, p. 83) afirma que:

[...] a cor tem a capacidade de captar rapidamente e sob um domínio emotivo a atenção do consumidor [...] ela acentua o clima desejado, criando um ambiente que se adequa ou se antecipa ao desejo do consumidor e à sua consequente ação para caracterizá-lo.

A cor, um dos fatores com grande peso na idealização da mensagem do outdoor, tem a capacidade de causar impacto e de captar a atenção do público, além de garantir altos graus de visibilidade à distância e de memória. No anúncio outdoor, de acordo com a OAAA, as combinações mais legíveis devem apresentar alto contraste e visibilidade. Se a tonalidade de uma cor estiver relacionada à luminosidade de outra, torna-se possível identificar contrastes cromáticos de grande potencial. Combinações entre 0 preto e cores intensamente luminosas, ou entre o branco e cores escuras (com baixa luminosidade), são responsáveis por produzir efeitos visuais de grande realce. Pelo contrário, cores opostas, com tonalidades bastante marcadas e luminosidade semelhante, promovem reduzido contraste visual. Além disso, as combinações entre cores adjacentes são consideradas fracas por apresentarem tonalidade e luminosidade semelhantes. Porém, o azul e o amarelo, ou o vermelho e o amarelo, são organizações cromáticas contrastantes. Estas observações podem ser constatadas no círculo cromático, apresentado na Figura 1.

A partir do estudo de Farina (1975) sobre o contraste cromático, elaborou-se uma tabela (Tabela 1) que auxilia no

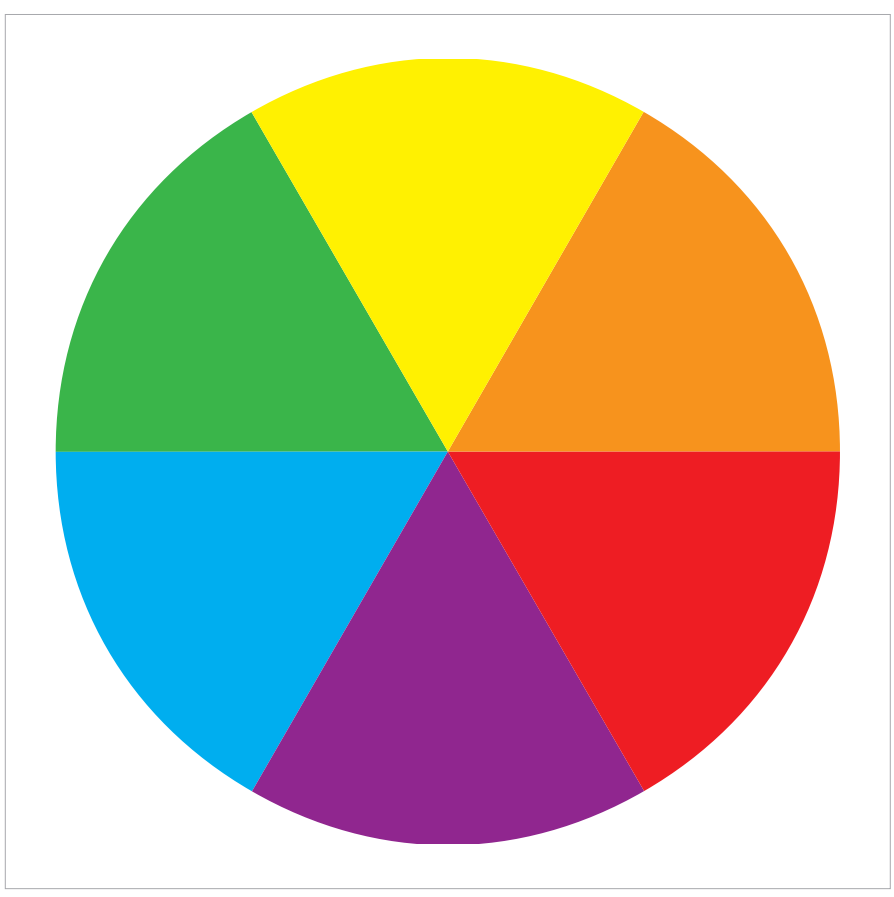

Figura 1: Círculo cromático.

Tabela 1: Grau de visibilidade e de recordação cromático.

\begin{tabular}{c|c|c}
\hline Contraste cromático & Grau de visibilidade à distância & Recordação \\
\hline Amarelo-preto & Elevado & Elevada \\
\hline Vermelho-verde & Ineficaz & Elevada \\
\hline Amarelo-azul & Elevado & - \\
\hline Azul-verde & Nulo & Reduzida \\
\hline Azul-branco & Reduzido & Reduzida \\
\hline Azul-vermelho & Reduzido & Reduzida \\
\hline Azul-preto & Reduzido & Elevada \\
\hline Vermelho-amarelo & Elevado & Reduzida \\
\hline Amarelo-verde & Reduzido &
\end{tabular}




\section{O outdoor político: da mensagem visual ao eleitor}

momento de escolha de duas cores de maior predominância no anúncio outdoor.

Tal como se verifica com a maioria das manifestações artísticas, a organização espacial dos elementos é essencial porque condiciona a orientação da leitura. A composição requer um estudo cuidadoso sobre a configuração e a combinação da informação visual que melhor estejam de acordo com os objetivos. Péninou (1994) destacou quatro configurações que podem ser encontradas com relativa frequência nas mensagens publicitárias ou propagandísticas:

- Focada (os elementos participantes da composição convergem para um ponto);

- Axial (a situação a ser destacada é colocada no centro);

- Em profundidade (a situação a ser destacada é colocada em primeiro plano);

- Sequencial (o olhar percorre todo o meio recaindo sobre o ponto a ser destacado - geralmente esta construção é em Z).

Para além das configurações inerentes à mensagem plástica, existe uma série de outros fatores que auxiliam na disposição dos elementos, considerando a elaboração da melhor solução visual, ou seja: o movimento e o ritmo, a proporção, $a$ atração e o contraste. Atendendo às características de uma mensagem bidimensional, o movimento é provavelmente a situação mais difícil de ser concretizada. Com base apenas na informação contida na mensagem, este elemento impõe certo dinamismo à peça. Intrinsecamente relacionado com o movimento surge o ritmo, definido como a repetição gradual, de intervalos regulares ou intercalados, de um ou vários elementos visuais presentes na mesma mensagem. Repetição simples, repetição alternada, ordenação dos espaços ou dos elementos da linguagem são as configurações mais comuns de organização rítmica presente nos outdoors, as quais interferem na captação da mensagem pelo público, proporcionando fácil e prolongada memorização da composição visual. Outro fator a ser considerado é a proporção. Caracterizada por estabelecer aparente harmonia entre os diversos elementos presentes na mensagem visual por meio do peso, do valor e do espaço, deve ser estudada e aplicada de forma a equilibrar a composição. Já a atração distingue-se pela capacidade de relacionamento entre os itens constituintes da mensagem: quanto mais próximos estiverem, mais forte é seu poder atrativo. Por fim, há o contraste, que é responsável por imprimir expressividade a certos elementos na composição. O peso, o tamanho, a posição espacial, a predominância de uma cor e o contorno são alguns dos instrumentos manipuláveis nas técnicas de comunicação visual, que permitem destacar determinados conteúdos.

No que diz respeito à textura, sua presença remete à dimensão sensorial. De fato, é possível perceber os veios da madeira, a rugosidade da pedra, e até as fissuras ou poros da pele através das qualidades táteis e visuais que entendidas, proporcionam, no domínio da linguagem plástica, uma noção de aparência da matéria por meio do contato visual. Esta perceção da textura, predominantemente tridimensional, é representada no plano bidimensional como recurso à fidelidade do conteúdo visual, levando em conta a realidade. Segundo Dondis (2000), a maioria das experiências táteis é visual. Isto porque, desde cedo, o ser humano aprende a criar com base em "[...] sensações visuais, outros tipos de sensações (táteis, auditivas, olfactivas)". As texturas, enquanto signos plásticos, apresentam a capacidade de estabelecer uma relação entre mensagem e observador: se a superfície for lisa, acentua-se o carácter de frieza, caracterizado por um distanciamento entre interlocutores; se for rugosa, visível dos efeitos de iluminação, a situação se inverte. Sousa (s.d.) afirma que "O efeito expressivo de uma textura regular [...] tem, em princípio, uma normalidade e uma racionalidade que difere substancialmente do efeito expressivo de texturas fortes, informais [...]".

De maneira geral, é possível distinguir dois tipos de texturas que, a partir de elementos visuais, provocam sensações: não táteis, considerando as representações visuais de superfícies lisas, caracterizadas por um distanciamento entre mensagem e observador; e táteis, inserindo as representações visuais que requerem uma perceção tátil, caracterizadas por uma aproximação entre mensagem e observador.

Normalmente associado à dimensão da imagem patente na mensagem visual, o enquadramento visual da imagem pode ser explicado como o "resultado suposto da distância entre o tema fotografado e a objetiva" (Joly, 1994). Ou seja, é o efeito fotográfico gerado pelo ângulo e pela objetiva. A escolha do ângulo condiciona a impressão que o observador tem da realidade. Por exemplo, o ângulo picado dá a sensação de esmagamento; por outro lado, o ângulo contrapicado dá a noção de ampliação; o ângulo normal, frontal, aproxima-se mais de uma situação real; e o ângulo diagonal, arrojado, possibilita novos pontos de vista, valorizando o fotógrafo. Em relação à objetiva, ou lente fotográfica, consideram-se: a objetiva de $50 \mathrm{~mm}$, mais próxima da abertura angular visual humana e, consequentemente, da visão do observador; a teleobjetiva, de focagem longa ou superior a $50 \mathrm{~mm}$, caracterizada pelo esmagamento da perspectiva 


\section{O outdoor político: da mensagem visual ao eleitor}

e pela diminuição da profundidade de campo; e a grande angular, de focagem curta ou inferior a $50 \mathrm{~mm}$, que proporciona nitidez do primeiro ao último plano.

No domínio da mensagem linguística, o foco é dado aos segmentos textuais com os quais habitualmente somos confrontados, visando compreender as estratégias que estão subjacentes. Em situações de elevada ambiguidade interpretativa, a linguagem verbal é um elemento imprescindível. Tal como advoga Joly (1994), "[...] a mensagem linguística é determinante na interpretação de uma "imagem" [...]."Em um anúncio, para garantir que o efeito desejado seja alcançado, recorre-se, na maioria das vezes, à colocação de unidades textuais: slogan, título ou caixas de texto. Essas unidades caracterizam-se por manter uma relação muito estreita com todos os outros elementos visuais, já que orientam a "leitura" que o observador faz do anúncio, ao mesmo tempo em que atraem e prendem sua atenção, suscitam interesse, causam impacto emocional, provocam desejo, e até conduzem à ação.

Trocadilhos, rimas, alusões e duplo-sentido são alguns dos jogos de linguagem mais frequentes em outdoors. $\mathrm{Na}$ elaboração de um bloco textual, o profissional deve ter em mente, para além do público a quem se dirige, o amplo leque de possibilidades que a linguagem verbal oferece. É consensual que o texto publicitário tira partido da combinação ou da manipulação das palavras, das frases, dos sentidos das palavras e até do próprio som.

Na comunicação política, muitas vezes tomam-se como base esses jogos linguísticos na elaboração dos blocos textuais, no intuito de melhor transmitir a mensagem. A exploração desses segmentos textuais também se verifica na qualidade do enunciador e do enunciatário, levando em consideração o receptor. De acordo com Pinto (1997), o enunciador "[...] pode assumir-se como um Eu ou um Nós, ou então despersonalizar o discurso, utilizando a terceira pessoa [...]", e o enunciatário, por sua vez, pode adotar uma de duas perspetivas: ou como uma "[...] figura discursiva não participante [ou como uma] personagem participante [...]".

\subsubsection{Análise conceptual}

Tomando como exemplo a observação de quatro outdoors, representativos das principais forças políticas em Portugal, utilizados em campanhas eleitorais ocorridas no contexto local, procuraremos perceber o comportamento dos diversos elementos constituintes da mensagem visual, abordados anteriormente, conforme apresentado na Tabela 2. Salienta-se apenas que o registo fotográfico dos outdoors ocorreu em período eleitoral, autárquicas e legislativas, sempre localizados em espaço público.
Considerando a análise realizada, verifica-se que a imagem fotográfica é uma presença constante em todos os outdoors. Pelo que foi possível observar, a criação de uma analogia com a realidade foi a condição imposta aos fotógrafos para trabaIharem a imagem dos candidatos. Este conceito de realidade aliada à fotografia (que, por si só, caracteriza-se por ser um meio de representação muito realista) torna os outdoors mais expressivos e enfatiza a proximidade com o público. A cor funcionou como um elemento atrativo, complementar e condicionador da interpretação da imagem (visível na generalidade dos outdoors políticos), ou então como um elemento identificativo do partido, como no outdoor "EU FICO", cuja referência cromática azul está associada ao Centro Democrático Social - Partido Popular (CDS-PP). No que diz respeito à composição, responsável pela orientação da "leitura" do anúncio, esta varia entre: focada, axial, de profundidade, quando o objetivo é destacar o candidato; e sequencial, quando se pretende imprimir algum movimento visual à mensagem, fixando-se na sigla do partido político ou no nome do candidato. Em relação aos formatos textuais, salienta-se o uso de frases curtas, objetivas e nominais. Poucos são os slogans que se concentram na primeira pessoa do singular, eu, ou os que apelam diretamente à segunda pessoa do singular, tu. Da mesma forma, poucos são aqueles que utilizam o "nós inclusivo", isto é, produzindo um efeito de colocação do receptor no papel de emissor, ou até de inclusão do público na autoria da mensagem. A maioria dos outdoors analisados utiliza um discurso em terceira pessoa, oscilando entre mensagens claramente projetadas no futuro, como propostas e promessas, e mensagens enunciando algum ideário "político" (de grande variação, por exemplo, com a apresentação das qualidades pessoais do candidato ou de características vagas de projetos políticos.

\section{Considerações finais}

Hoje, principalmente nos países democráticos, verifica-se que cada vez mais é indispensável a realização de um estudo cuidadoso de todas as variáveis que influenciam a decisão do voto. Nesse sentido, também o anúncio político requer uma análise no momento de sua idealização e criação, considerando o objetivo final pretendido: angariação de votos. A mensagem visual obedece, assim, a pressupostos mais ou menos estabelecidos de desenvolvimento e de aplicação dos seus conteúdos.

Com a expansão da sociedade, percebida especialmente no último século, o outdoor tornou-se um veículo de comunicação de ideologias, com a missão de promover o diálogo entre o emissor e o receptor, em uma comunicabilidade de compromisso notório entre aqueles dois comunicadores, proporcionando a disseminação da mensagem política, potenciando-a. 
Tabela 2: Análise da mensagem plástica e linguística em alguns outdoors políticos.
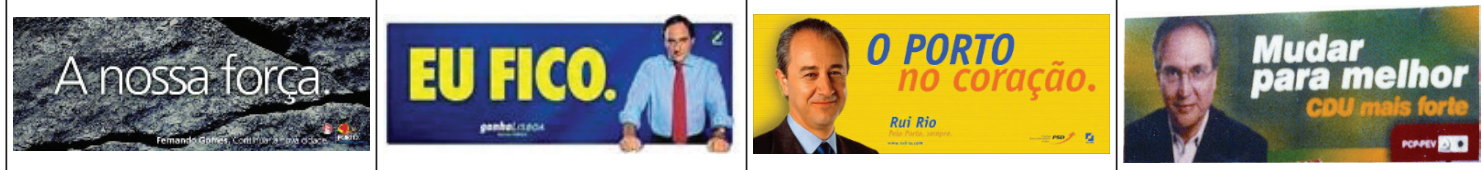

Cor

\begin{tabular}{|c|c|c|c|c|}
\hline Contraste & Tons de cinza e branco & Azul e amarelo & $\begin{array}{l}\text { Amarelo e azul } \\
\text { (predominante) }\end{array}$ & $\begin{array}{c}\text { Mescla de verde } \\
\text { e amarelo }\end{array}$ \\
\hline Grau de legibilidade & Médio & Elevado & Elevado & Elevado \\
\hline Grau de recordação & Elevado & Elevado & Elevado & Elevado \\
\hline Composição & - & - & - & - \\
\hline Focada & - & $\begin{array}{c}\text { A orientação visual } \\
\text { tende para a imagem do } \\
\text { candidato. }\end{array}$ & - & - \\
\hline Axial & $\begin{array}{l}\text { Centralização do } \\
\text { conteúdo a ser } \\
\text { destacado. }\end{array}$ & - & - & - \\
\hline Em profundidade & - & - & $\begin{array}{c}\text { A imagem do candidato } \\
\text { em primeiro plano. }\end{array}$ & - \\
\hline Sequencial & - & - & 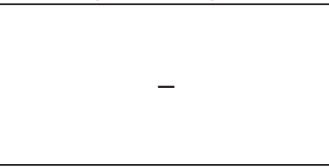 & $\begin{array}{l}\text { O olhar do observador } \\
\text { percorre os elementos } \\
\text { visuais, terminando no } \\
\text { símbolo do partido. }\end{array}$ \\
\hline
\end{tabular}

\section{Textura}

Tátil

Visualização da textura de granito.

O fundo assemelha-se

à textura de um tecido acetinado.

Não tátil

Enquadramento, ângulo do ponto de vista e escolha da objetiva

\begin{tabular}{l} 
Picado \\
\hline Contrapicado \\
\\
Normal, frontal
\end{tabular}

Normal, frontal

Diagonal Mensagem linguística

\begin{tabular}{|c|c|}
\hline- & - \\
\hline $\begin{array}{l}\text { Lentes fotográficas de } \\
\text { grande abertura. } \\
\text { Focal curta, com } \\
\text { reduzida profundidade } \\
\text { de campo. }\end{array}$ & $\begin{array}{l}\text { Plano mais fechado que } \\
\text { um plano médio. } \\
\text { Plano próximo. } \\
\text { Lente fotográfica } \\
\text { de } 50 \mathrm{~mm} \text {. }\end{array}$ \\
\hline- & - \\
\hline
\end{tabular}

"A nossa vontade."
Frases curtas. Ausência
de verbo na frase.
Discurso de primeira
pessoa, centralização no
"nós inclusivo".
"Continuar a nova
cidade."
Uso do infinitivo.
Discurso de terceira
pessoa (mensagem
impessoal).

"EU FICO."

Frase curta.

Discurso na primeira pessoa, centralização no emissor.
"O Porto no coração." Frase curta. Ausência de verbo na frase.

Discurso de terceira pessoa (mensagem impessoal).

"Pelo Porto, sempre."

Frases curtas. Ausência de verbo na frase.

Uso do infinitivo.

Discurso de terceira pessoa (mensagem impessoal).
"Mudar para melhor" Frase curta.

Uso do infinitivo. Discurso de terceira pessoa (mensagem impessoal).

"CDU mais forte"

Frase curta. Ausência de verbo.

Discurso de terceira pessoa (mensagem impessoal). 


\section{O outdoor político: da mensagem visual ao eleitor}

Considerando a observação e o estudo dos diversos outdoors envolvidos na investigação, foi possível perceber que determinadas técnicas são repetidas, especialmente pelo fato de proporcionarem realismo e objetividade à mensagem comunicacional.

\section{Referências}

Barnicoat, John. Los Carteles: su historia y su lenguaje. Barcelona: Gustavo Gili, 1997.

Camilo, Eduardo. Vivo Cartaz!! Manifesto em torno de um romantismo político. Disponível em <http:// www.bocc.ubi. pt/>. Acesso em 20 out. 2002.

Carmona, Matthew; Heath, Tim; Oc, Taner; Tiesdell, Steve. Public Spaces - Urban Space: the dimensions of urban design. Oxford: Elsevier, 2003.

DonDIS, Donnis. La sintaxe de la imagen: introducción al alfabeto visual. Barcelona: Gustavo Gili, 2000.

Farina, Modesto. Psicodinâmica das Cores em Publicidade. São Paulo: Editora Edgar Blucher, 1975.

Joannis, Henri. O Processo de Criação Publicitária: Estratégia, Concepção e Realização de Mensagens Publicitárias. Mem-Martins: Edições Cetop, 1998.
Aprofundar este estudo a outdoors políticos inseridos em contextos sociais diferentes, tendo por base a estrutura de análise criada, ou partindo desta, no sentido de melhoria ou de adaptação à realidade para uma estrutura renovada, poderá constituir parte de uma investigação futura.

Joly, Martine. Introdução à Análise da Imagem. In: Arte e Comunicação 68. Lisboa: Edições 70, 1994.

MaArek, Philippe. Communication et marketing de l'homme politique. Paris: Litec, 1992.

Moles, Abraham. O cartaz. In: Debates. São Paulo: Editorial Perspectiva, 1969.

Outdoor Advertising Association of America. Disponível em <http://www.oaaa.org/OutofHomeAdvertising/HistoryofOOH. aspx>. Acesso em 24 out. 2013.

PInto, Alexandra Guedes. Publicidade: Um discurso de Sedução. Porto: Porto Editora, 1997.

RoseWARNE, Lauren. Outdoor advertising and public space: Gender, fear, and feminism. In: Women's Studies international Fórum 28, Elsevier, p. 67-78, 2005.

Sousa, Rocha de.Desenho. Textos Pré-Universitários, s.n.t., s.d. 